\title{
Infections with Giardia duodenalis and Entamoeba histolytical Entamoeba dispar as Hidden and Prevalent Conditions in Periurban Communities in the State of Rio de Janeiro, Brazil
}

\author{
Deiviane A. Calegar $\mathbb{D}^{1},{ }^{1}$ Kerla J. L. Monteiro, ${ }^{1,2}$ Andressa B. Gonçalves, ${ }^{1}$ Márcio N. Boia, ${ }^{3}$ \\ Lauren H. Jaeger, ${ }^{1,4}$ Beatriz C. Nunes, ${ }^{1,5}$ and Filipe A. Carvalho-Costa ${ }^{1,2}$ \\ ${ }^{1}$ Fundação Oswaldo Cruz, Instituto Oswaldo Cruz, Laboratório de Epidemiologia e Sistemática Molecular, \\ Rio de Janeiro RJ, Brazil \\ ${ }^{2}$ Escritório Técnico Regional-Fundação Oswaldo Cruz, Rua Magalhães Filho, 519, Centro/Norte, Teresina, Piauí, Brazil \\ ${ }^{3}$ Fundação Oswaldo Cruz, Instituto Oswaldo Cruz, Laboratório de Biologia e Parasitologia de Mamíferos Silvestres Reservatórios, \\ Rio de Janeiro RJ, Brazil \\ ${ }^{4}$ Faculdade de Farmácia, Universidade Federal de Juiz de Fora, Rua José Lourenço Kelmer, S/n-Campus Universitário, \\ Bairro São Pedro, Juiz de Fora, Minas Gerais, Brazil \\ ${ }^{5}$ Faculdade de Medicina de Petrópolis (FMP)/Faculdade Arthur Sá Earp Neto (FASE), Rua Machado Fagundes, 326, Cascatinha, \\ Petrópolis, Rio de Janeiro, Brazil
}

Correspondence should be addressed to Deiviane A. Calegar; deivianecalegar@gmail.com

Received 10 April 2020; Accepted 27 June 2020; Published 14 July 2020

Academic Editor: Pedro P. Chieffi

Copyright (C) 2020 Deiviane A. Calegar et al. This is an open access article distributed under the Creative Commons Attribution License, which permits unrestricted use, distribution, and reproduction in any medium, provided the original work is properly cited.

\begin{abstract}
This study aims to assess the prevalence, distribution, and etiological profile of intestinal parasitism in children living in periurban areas in Cachoeiras de Macacu, Rio de Janeiro, Brazil. A community-based cross-sectional survey $(n=479)$ was carried out. Prevalence of infection with G. duodenalis and E. histolytica/E. dispar was $8.6 \%(n=41)$ and $13.4 \%(n=64)$, respectively. Infection with $G$. duodenalis was significantly more frequent among children living in poor families (24/187 (12.8\%) vs. 16/272 (5.9\%); prevalence ratio $(\mathrm{PR})=2.18 ; 95 \%$ confidence interval $(\mathrm{CI})=1.19-3.99 ; p=0.011)$. This difference was also significant for infection with any pathogenic parasite $(43 / 187(23 \%)$ vs. 40/272 $(14 / 7 \%)$; $\mathrm{PR}=1.56 ; 95 \% \mathrm{CI}=1.06-2.30 ; p=0.026)$. In addition, people residing in houses with more than four inhabitants showed significantly higher positivity for infections with G. duodenalis and with E. histolytica/E. dispar (22/138 (15.9\%) vs. 16/311 (5.1\%); $\mathrm{PR}=3.09 ; 95 \% \mathrm{CI}=1.68-5.71 ; p<0.001$ for G. duodenalis and 32/ $138(23.2 \%)$ vs. $30 / 311$ (9.6\%); $\mathrm{PR}=2.40 ; 95 \% \mathrm{CI}=1.52-3.79 ; p<0.001$ for E. histolytica/E. dispar). Laboratory diagnosis of protozoan enteric infections and effective drugs for their treatment are unmet goals in the primary health care system. Therefore, giardiasis and amebiasis are neglected conditions.
\end{abstract}

\section{Introduction}

Some species of protozoa with variable pathogenic potential inhabit the human intestine. Giardia duodenalis and Entamoeba histolytica are among those that are known to be harmful [1]. G. duodenalis negatively influences the development of children in a complex pathogenesis involving enterocyte apoptosis and immune-mediated reactions at the small intestine [2,3]. Giardiasis usually not only presents an endemic epidemiological behaviour in developing countries but also causes outbreaks of diarrhoea in developed countries $[4,5]$. Prevalence rates range from $10 \%$ to $30 \%$ in Brazil. In children hospitalized due to acute diarrhoea in Rio de Janeiro, the positivity rate was $4.7 \%[6,7]$.

E. histolytica infections, despite being most frequently asymptomatic, have invasive potential and can be associated with dysentery and hepatic abscesses [8]. Amebiasis is also associated with poor water quality and sanitation, and its 
prevalence is substantially higher in developing countries [6]. In Brazil, prevalence rates of infection in nondiarrhoeal stools range from $12 \%$ to $25 \%$ in urban settings with poor sanitation infrastructure in Amazonian Brazil and 21\% in semiarid regions under water stress in the northeast of the country. E. histolytica is indistinguishable, under light microscopy, from species considered to be nonpathogenic, for instance Entamoeba dispar. This leads to the use of the nomenclature E. histolytica/E. dispar complex, which may include other species such as Entamoeba moshkovskii and Entamoeba hartmanni [9].

Among the enteric parasites, soil-transmitted helminths (STHs) are targeted by preventive chemoprophylaxis with a periodic $400 \mathrm{mg}$ albendazole dose [10]. This may have shaped the etiological profile of parasitic intestinal infections towards a higher frequency of protozoa detection [11]. There are no antiprotozoal drugs compatible with chemoprophylaxis, and treatment must be individualized with the dose being adjusted for body weight [12-14]. The most available drug, metronidazole, should be taken for five days at eighthour intervals [15]. A single dose drug option, secnidazole also requires individualized body weight prescription [16]. Nitazoxanide, a more recently proposed option, is not economically viable for use on a community scale [17]. The present study aims to characterize the prevalence, distribution, and etiological profile of intestinal parasitism in children living in periurban areas with poor sanitation in the state of Rio de Janeiro, Brazil.

\section{Materials and Methods}

2.1. Description of the Studied Area. The study was carried out in Papucaia, Ribeira, and Marubaí in the municipality of Cachoeiras de Macacu, Rio de Janeiro (Figure 1).

Papucaia and Ribeira are periurban districts, in which almost 3,000 families (approximately 17,000 inhabitants) live. In general, in the communities of Papucaia and Ribeira, treated piped water is supplied to households. In homes, water is stored in tanks and consumed directly, without any further treatment. There is a sewage system, and evacuation is practiced in latrines inside the houses. Solid excreta, however, is discharged without treatment into water bodies such as rivers. In Marubaí, the drinking water comes from artesian wells.

2.2. Study Design and Sampling Strategy. A communitybased cross-sectional survey was carried out in 2018 and included 479 children aged 0-15 years (209 in Papucaia, 180 in Ribeira, and 90 in Marubaí). Sampling included $36.7 \%$ of children living in Papucaia, 30.2\% of those in Ribeira, and $70.8 \%$ of those in Marubaí. With the sample size reached, we had an $80 \%$ confidence level to identify prevalence rates with an expected frequency of $20 \%$ and a margin of error of $2 \%$. The researchers asked questions in a standardized questionnaire to obtain sociodemographic and sanitation data. Per capita household income was calculated by summing the income of all household members and dividing by the number of residents. Children were classified as poor when living in families with incomes below $\mathrm{R} \$ 178$ (equivalent to approximately 44 USD) and $43.2 \%$ of children were classified as poor.

2.3. Ethical Approval. The study was previously approved by the Research Ethics Committee of Instituto Oswaldo Cruz/ Fiocruz, license number CAAE: 12125713.5.0000.5248.

2.4. Parasitological Examinations. Three faecal samples collected on successive days were examined per child. Samples were processed through Ritchie's modified ethyl acetate sedimentation technique [18].

2.5. Statistical Analyses. Data were presented descriptively, and statistical analyses were performed with SPSS ${ }^{\circledR}$ (IBM Corp., Armonk, NY, USA) as prevalence rates of different parasite species in distinct sociodemographic categories. Prevalence ratios and respective 95\% CIs were calculated. The statistical significance of the associations was assessed by Fisher's exact test, with a significance threshold of $p<0.05$.

\section{Results}

Among the children included in the study, the prevalence of infection by any organism was 19.4\% (93/479). Figure 2 presents the positivity rates for distinct pathogenic organisms by community. Eight children (1.7\%) were positive for STH (A. lumbricoides $(n=5)$, hookworms $(n=2)$, or $T$. trichiura $(n=1))$.

The positivity rate for any pathogenic protozoan was $17.9 \%$. Table 1 shows the distribution of infections with Giardia duodenalis and E. histolytica/E. dispar. Prevalence of infection with G. duodenalis and E. histolytica/E. dispar was $8.6 \%(n=41)$ and $13.4 \%(n=64)$, respectively, in all localities. Infection with $G$. duodenalis was significantly more frequent among children living in poor families. This difference was also significant for infection with any pathogenic parasite. In addition, people residing in houses with more than four inhabitants showed significantly higher positivity for infections with $G$. duodenalis and E. histolytica/E. dispar (Table 1). Prevalence rates of infection with pathogenic protozoa were significantly lower among children aged up to two years. There were no significant differences in the positivity rates across the three studied locations (Marubaí, Papucaia, and Ribeira).

In relation to positivity for nonpathogenic protozoa, the prevalence rates were $9.2 \%(n=44)$ for Endolimax nana, $1.3 \%(n=6)$ for Iodamoeba butschlii, and 5.8\% $(n=28)$ for Entamoeba coli.

Among the 93 positive samples for any pathogenic organism, 86 had pathogenic protozoa, eight had STH, and one had both. Anthelmintics were reported to be used in 136 children $(27.6 \%)$ during the period from one to six months prior to faecal collection. Information on the presence of diarrhoea was available for 439 (91.7\%) of 479 children. It 


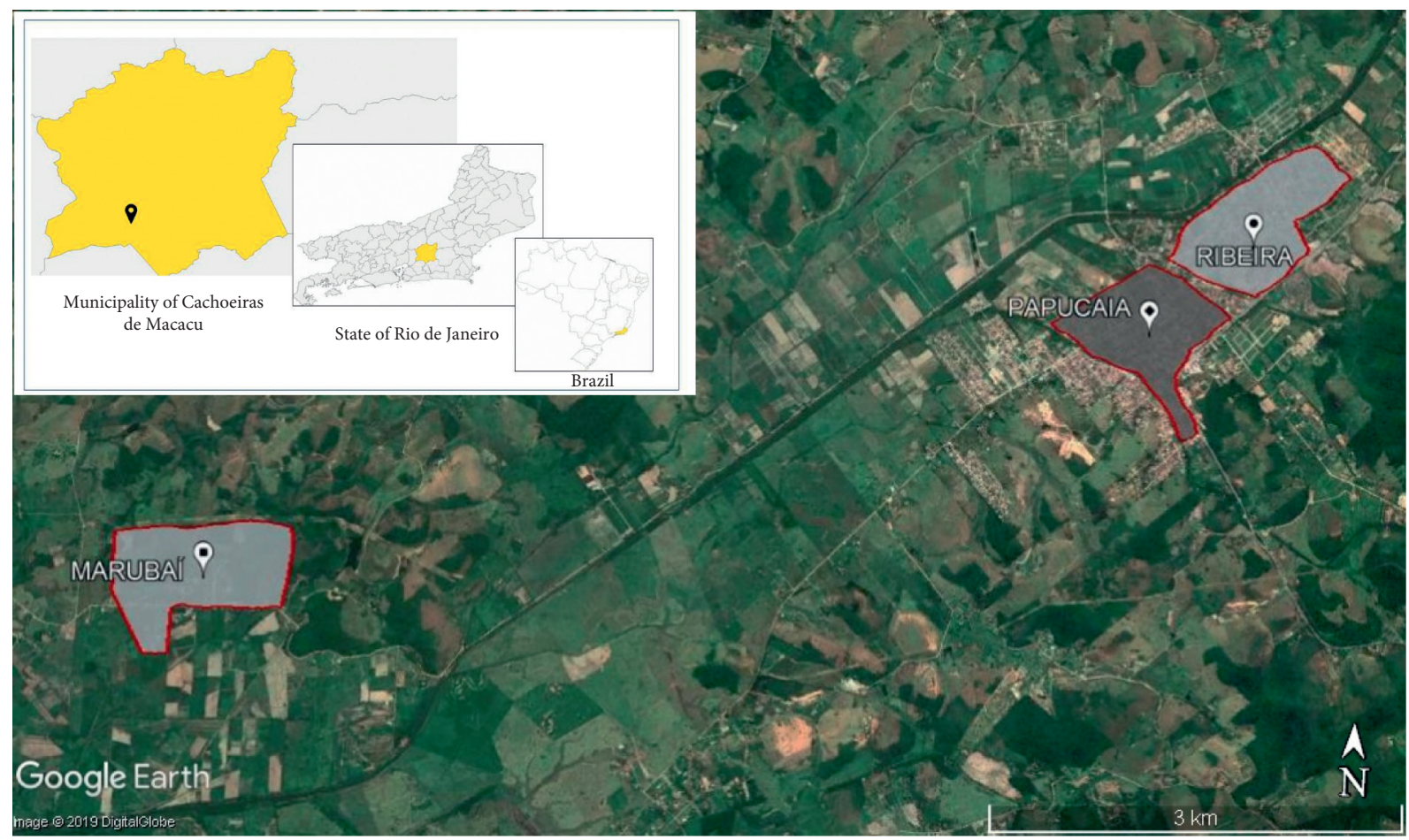

FIgURE 1: Basic rocket ship design. The rocket ship is propelled with three thrusters and features a single viewing window. The nose cone is detachable upon impact.

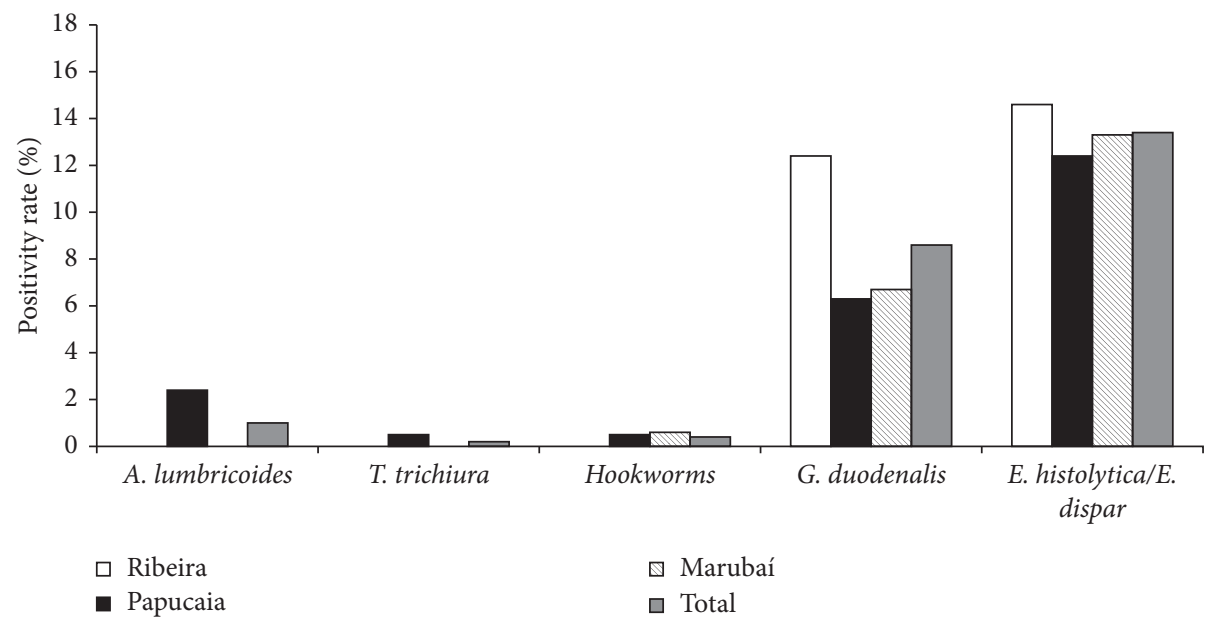

FIGURe 2: Prevalence rates of infections by different intestinal parasites in children aged 0-14 years in three communities of Cachoeiras de Macacu, Rio de Janeiro, 2018.

was observed that $23(5.2 \%)$ presented diarrhoea at some point previous to faecal sample collection. Of these, 16 reported symptoms within 15 days before collection, two had diarrhoea within 15 to 30 days prior to collection, and five reported it more than one month before. There were no significant differences in positivity rates for different parasites among children who reported and did not report diarrhoea $(37 / 416(8.9 \%)$ vs. $0 / 23(0 \%) ; p=0.243$ for $G$. duodenalis and $60 / 416(14.4 \%)$ vs. $2 / 23(8.7 \%) ; p=0.757$ for E. histolytica/E. dispar.

\section{Discussion}

This study revealed the predominance of protozoa among organisms that parasitize the digestive tract of children in a periurban area of low socioeconomic status in the state of Rio de Janeiro, Brazil. Similar results were found in other studies conducted in Rio de Janeiro [19-21]. Regarding infections in different age groups, significantly higher positivity rates in children aged from three to six were observed, suggesting a greater exposure at these ages. 
Table 1: Distribution of Giardia duodenalis and E. histolytica/E. dispar infections in Cachoeiras de Macacu, RJ, 2018.

\begin{tabular}{|c|c|c|c|c|c|c|c|c|c|}
\hline \multirow[b]{2}{*}{ Locality } & \multicolumn{3}{|c|}{ Giardia duodenalis } & \multicolumn{3}{|c|}{ E. histolytica/E. dispar } & \multicolumn{3}{|c|}{ Any pathogenic protozoa } \\
\hline & Prevalence & $\begin{array}{c}\text { Prevalence } \\
\text { ratio** }^{* *}\end{array}$ & $\begin{array}{c}p \\
\text { value }\end{array}$ & Prevalence & $\begin{array}{c}\text { Prevalence } \\
\text { ratio** }\end{array}$ & $\begin{array}{c}p \\
\text { value }\end{array}$ & Prevalence & $\begin{array}{c}\text { Prevalence } \\
\text { ratio** }^{* *}\end{array}$ & $\begin{array}{c}p \\
\text { value }\end{array}$ \\
\hline Papucaia & $\begin{array}{l}13 / 209 \\
(6.2 \%)\end{array}$ & 1 & & $\begin{array}{l}26 / 209 \\
(12.4 \%)\end{array}$ & 1 & & $31 / 209(14.8 \%)$ & 1 & \\
\hline Marubaí & $6 / 90(6.7 \%)$ & $\begin{array}{c}1.07 \\
(0.42-2.73)\end{array}$ & 1 & $\begin{array}{c}12 / 90 \\
(13.3 \%)\end{array}$ & $\begin{array}{c}1.07 \\
(0.56-2.02)\end{array}$ & 0.850 & $15 / 90(16.7 \%)$ & $\begin{array}{c}1.12 \\
(0.63-1.97)\end{array}$ & 0.727 \\
\hline Ribeira & $\begin{array}{l}22 / 180 \\
(12.2 \%)\end{array}$ & $\begin{array}{c}1.96 \\
(1.01-3.78)\end{array}$ & 0.049 & $\begin{array}{l}26 / 180 \\
(14.4 \%)\end{array}$ & $\begin{array}{c}1.16 \\
(0.70-1.92)\end{array}$ & 0.654 & $40 / 180(22.2 \%)$ & $\begin{array}{c}1.49 \\
(0.97-2.29)\end{array}$ & 0.066 \\
\hline \multicolumn{10}{|c|}{ Age group (years) } \\
\hline $0-2$ & $2 / 94(2.1 \%)$ & 1 & & $4 / 94(4.3 \%)$ & 1 & & $6 / 94(6.4 \%)$ & 1 & \\
\hline $3-6$ & $\begin{array}{c}17 / 154 \\
(11 \%)\end{array}$ & $\begin{array}{c}5.18 \\
(1.22-21.95)\end{array}$ & 0.012 & $\begin{array}{l}23 / 154 \\
(14.9 \%)\end{array}$ & $\begin{array}{c}3.50 \\
(1.25-9.83)\end{array}$ & 0.010 & $32 / 154(20.8 \%)$ & $\begin{array}{c}3.25 \\
(1.41-7.49)\end{array}$ & 0.001 \\
\hline $7-15$ & $\begin{array}{l}22 / 231 \\
(9.5 \%)\end{array}$ & $\begin{array}{c}4.47 \\
(1.07-18.65)\end{array}$ & 0.019 & $\begin{array}{c}37 / 231 \\
(16 \%)\end{array}$ & $\begin{array}{c}3.76 \\
(1.38-10.26)\end{array}$ & 0.002 & $48 / 231(20.8 \%)$ & $\begin{array}{c}3.25 \\
(1.44-7.34)\end{array}$ & $<0.001$ \\
\hline \multicolumn{10}{|c|}{$\begin{array}{l}\text { Income per capita } \\
\text { per month* (USD) }\end{array}$} \\
\hline$<44 \mathrm{USD}^{1}$ & $\begin{array}{l}24 / 187 \\
(12.8 \%)\end{array}$ & $\begin{array}{c}2.18 \\
(1.19-3.99)\end{array}$ & 0.011 & $\begin{array}{l}31 / 187 \\
(16.6 \%)\end{array}$ & $\begin{array}{c}1.45 \\
(0.91-2.30)\end{array}$ & 0.127 & $43 / 187(23 \%)$ & $\begin{array}{c}1.56 \\
(1.06-2.30)\end{array}$ & 0.026 \\
\hline$\geq 44 \mathrm{USD}^{2}$ & $\begin{array}{l}16 / 272 \\
(5.9 \%)\end{array}$ & 1 & & $\begin{array}{l}31 / 272 \\
(11.4 \%)\end{array}$ & 1 & & $40 / 272(14.7 \%)$ & 1 & \\
\hline \multicolumn{10}{|c|}{$\begin{array}{l}\text { Number of persons } \\
\text { in the household }\end{array}$} \\
\hline$\leq 4$ & $\begin{array}{l}16 / 311 \\
(5.1 \%)\end{array}$ & 1 & & $\begin{array}{l}30 / 311 \\
(9.6 \%)\end{array}$ & 1 & & $41 / 311(13.2 \%)$ & 1 & \\
\hline$>4$ & $\begin{array}{l}22 / 138 \\
(15.9 \%)\end{array}$ & $\begin{array}{c}3.09 \\
(1.68-5.71)\end{array}$ & $<0.001$ & $\begin{array}{l}32 / 138 \\
(23.2 \%)\end{array}$ & $\begin{array}{c}2.40 \\
(1.52-3.79)\end{array}$ & $<0.001$ & $40 / 138(29 \%)$ & $\begin{array}{c}2.19 \\
(1.49-3.23)\end{array}$ & $<0.001$ \\
\hline \multicolumn{10}{|l|}{ Gender } \\
\hline Male & $\begin{array}{l}21 / 250 \\
(8.4 \%)\end{array}$ & 1 & & $\begin{array}{l}39 / 250 \\
(15.6 \%)\end{array}$ & 1 & & $49 / 250(19.6 \%)$ & 1 & \\
\hline Female & $20 / 229(8.7)$ & $\begin{array}{c}1.03 \\
(0.57-1.86)\end{array}$ & 1 & $\begin{array}{l}25 / 229 \\
(10.9 \%)\end{array}$ & $\begin{array}{c}0.69 \\
(0.43-1.11)\end{array}$ & 0.141 & $37 / 229(16.2 \%)$ & $\begin{array}{c}0.82 \\
(0.55-1.21)\end{array}$ & 0.342 \\
\hline
\end{tabular}

${ }^{*}$ USD $1=$ BRL $4 .{ }^{* *} 95 \%$ CI. ${ }^{1}$ Poverty. ${ }^{2}$ Not poverty.

The control strategies for intestinal parasites aim for the elimination of STHs, and there is a trend of reduction in their prevalence [22]. In this study, almost a third of children had used drugs such as albendazole and mebendazole during the six months before faecal examination. Despite this, studies have demonstrated that in certain regions of Brazil-mainly in rural areas-some STH foci persist $[23,24]$.

The administration of anthelmintic drugs without appropriate diagnostic tests has made it difficult to diagnose infection with protozoa, making giardiasis and amoebiasis underdiagnosed diseases. Techniques capable of detecting intestinal protozoan infections have not been performed in public health laboratories. More recently, enzyme immunoassay has replaced microscopic examination in most clinical laboratories [25]. However, the cost of these tests does not yet allow their use for large-scale diagnosis in primary health care.

In this study, although a few children reported diarrhoea in the period before stool collection, no diarrhoeal samples were found, indicating chronic and apparently asymptomatic infections. Although recognized as a cause of epidemic waterborne diarrhoeal disease and traveller's diarrhoea in developed countries, the role of $G$. duodenalis as an etiological agent of diarrhoeal diseases in developing countries is less certain [26, 27]. Interestingly, recent studies failed to characterize $G$. duodenalis as a pathogen associated with diarrhoeal disease in children in developing countries. Instead, giardiasis presents as chronic and apparently asymptomatic or causes mild illness of the small intestine, associated with chronic nutrient spoliation, and deficits in physical development due to interference with absorptive function $[28,29]$.

Infection by E. histolytica/E. dispar was observed in the three studied locations in all age groups. The positivity rate was akin to that described in similar studies conducted in other regions. Among the positive children, none had symptoms compatible with invasive conditions that could indicate the presence of amoebic dysentery. It should be in mind that the clinical manifestations of E. histolytica/E. dispar infection have variable symptoms, from subclinical colonization to severe invasive conditions. It is not possible to differentiate, under light microscopy, the species of the $E$. histolytica/E. dispar complex. Additionally, it is possible that, in the studied communities, low virulence strains predominate, as observed in several countries. As faecal-borne diseases, giardiasis and amoebiasis are sensitive to sanitation conditions and the supply of drinking water. Thus, they have a strong social determination and are associated with poverty. Household crowding, poor sanitation, and water supply have been associated with intestinal protozoa infection [30, 31]. 


\section{Conclusions}

This study illustrates the changing etiological profile of intestinal parasitism in periurban areas in Brazil and points to the need for the improvement of control strategies, which should include enhancements in sanitation. Laboratory diagnosis of protozoan enteric infections and effective drugs for their treatment are unmet goals in the primary health care system. Therefore, giardiasis and amebiasis are neglected conditions.

\section{Data Availability}

The data used to support this study are available from the corresponding author upon request. The data are not publicly available because they contain information that could compromise the privacy of research participants.

\section{Conflicts of Interest}

The authors declare that they have no conflicts of interest.

\section{Acknowledgments}

The authors thank all the professionals involved, in particular, communitarian health agents within the Family Health Strategy program. This study was financed in part by the Coordenação de Aperfeiçoamento de Pessoal de Nível Superior, Brasil (CAPES) (finance code 001) and Foundation Oswaldo Cruz (FIOCRUZ).

\section{References}

[1] K. Chifunda and P. Kelly, "Parasitic infections of the gut in children," Paediatrics and International Child Health, vol. 39, no. 1, pp. 65-72, 2019.

[2] V. Vivancos, I. González-Alvarez, M. Bermejo, and M. Gonzalez-Alvarez, "Giardiasis: characteristics, pathogenesis and new insights about treatment," Current Topics in Medicinal Chemistry, vol. 18, no. 15, pp. 1287-1303, 2018.

[3] J. A. Cotton, J. K. Beatty, and A. G. Buret, "Host parasite interactions and pathophysiology in Giardia infections," International Journal for Parasitology, vol. 41, no. 9, pp. 925933, 2011.

[4] S. J. Campbell, S. V. Nery, C. A. D’Este et al., "Water, sanitation and hygiene related risk factors for soil-transmitted helminth and Giardia duodenalis infections in rural communities in Timor-Leste," International Journal for Parasitology, vol. 46, no. 12, pp. 771-779, 2016.

[5] H. E. Reses, J. W. Gargano, J. L. Liang et al., "Risk factors for sporadic Giardia infection in the USA: a case-control study in Colorado and Minnesota," Epidemiology and Infection, vol. 146, no. 9, pp. 1071-1078, 2018.

[6] A. P. Dias, D. Calegar, F. A. Carvalho-Costa et al., "Assessing the influence of water management and rainfall seasonality on water quality and intestinal parasitism in rural northeastern Brazil," Journal of Tropical Medicine, vol. 2018, Article ID 8159354, 10 pages, 2018.

[7] B. C. Nunes, D. A. Calegar, M. G. Pavan et al., "Genetic diversity of Giardia duodenalis circulating in three Brazilian biomes," Infection, Genetics and Evolution, vol. 59, pp. 107112, 2018.
[8] M. Kantor, A. Abrantes, A. Estevez et al., "Entamoeba histolytica: updates in clinical manifestation, pathogenesis, and vaccine development," Canadian Journal of Gastroenterology and Hepatology, vol. 2018, Article ID 4601420, 6 pages, 2018.

[9] D. A. Calegar, B. C. Nunes, K. J. Monteiro et al., "Frequency and molecular characterisation of Entamoeba histolytica, Entamoeba dispar, Entamoeba moshkovskii, and Entamoeba hartmanni in the context of water scarcity in northeastern Brazil," Memórias do Instituto Oswaldo Cruz, vol. 111, no. 2, pp. 114-119, 2016.

[10] J. C. Dunn, A. A. Bettis, N. Y. Wyine et al., "Soil-transmitted helminth reinfection four and six months after mass drug administration: results from the delta region of Myanmar," PLoS Neglected Tropical Diseases, vol. 13, no. 2, Article ID e0006591, 2019.

[11] F. Macchioni, H. Segundo, S. Gabrielli et al., "Dramatic decrease in prevalence of soil-transmitted helminths and new insights into intestinal protozoa in children living in the Chaco region, Bolivia," The American Journal of Tropical Medicine and Hygiene, vol. 92, no. 4, pp. 794-796, 2015.

[12] J. A. Turkeltaub, T. R. McCarty, and P. J. Hotez, "The intestinal protozoa: emerging impact on global health and development," Current Opinion in Gastroenterology, vol. 31, no. 1, pp. 38-44, 2015.

[13] S. M. Fletcher, D. Stark, J. Harkness, and J. Ellis, "Enteric protozoa in the developed world: a public health perspective," Clinical Microbiology Reviews, vol. 25, no. 3, pp. 420-449, 2012.

[14] J. A. Iza, S. N. Iza, and M. J. Olivera, "Giardiasis: report of a case refractory to treatment," Infez Med, vol. 27, no. 3, pp. 336-339, 2019.

[15] A. K. C. Leung, A. A. M. Leung, A. H. C. Wong, C. M. Sergi, and J. K. M. Kamsites, "Giardiasis: an overview," Recent Patents on Inflammation \& Allergy Drug Discovery, vol. 13, no. 2, 2019.

[16] A. A. Escobedo, R. Cañete, M. E. Gonzalez, A. Pareja, S. Cimerman, and P. Almirall, "A randomized trial comparing mebendazole and secnidazole for the treatment of giardiasis," Annals of Tropical Medicine \& Parasitology, vol. 97, no. 5, pp. 499-504, 2003.

[17] T. M. Galeh, A. Kazemi, M. Mahami-Oskouei et al., "Introducing nitazoxanide as a promising alternative treatment for symptomatic to metronidazole-resistant giardiasis in clinical isolates," Asian Pacific Journal of Tropical Medicine, vol. 9, no. 9, pp. 887-892, 2016.

[18] K. H. Young, S. L. Bullock, D. M. Melvin, and C. L. Spruill, "Ethyl acetate as a substitute for diethyl ether the formalinether sedimentation technique," Journal of Clinical Microbiology, vol. 10, no. 6, pp. 852-853, 1979.

[19] C. F. Ignacio, M. E. C. D. Silva, N. B. Handam et al., "Socioenvironmental conditions and intestinal parasitic infections in Brazilian urban slums: a cross-sectional study," Revista do Instituto de Medicina Tropical de São Paulo, vol. 59, 2017.

[20] C. P. Faria, G. M. Zanini, G. S. Dias et al., "Geospatial distribution of intestinal parasitic infections in Rio de Janeiro (Brazil) and its association with social determinants," PLoS Neglected Tropical Diseases, vol. 11, no. 3, Article ID e0005445, 2017.

[21] C. V. Barbosa, M. M. Barreto, R. D. J. Andrade et al., "Intestinal parasite infections in a rural community of Rio de Janeiro (Brazil): prevalence and genetic diversity of Blastocystis subtypes," PLoS One, vol. 13, no. 3, Article ID e0193860, 2018. 
[22] F. Chammartin, L. H. Guimarães, R. G. Scholte, M. E. Bavia, J. Utzinger, and P. Vounatsou, "Spatio-temporal distribution of soil-transmitted helminth infections in Brazil," Parasites and Vectors, vol. 7, no. 1, p. 440, 2014.

[23] K. J. L. Monteiro, E. R. C. D. Reis, B. C. Nunes et al., "Focal persistence of soil-transmitted helminthiases in impoverished areas in the State of Piaui, Northeastern Brazil," Revista do Instituto de Medicina Tropical de São Paulo, vol. 60, p. e24, 2018.

[24] J. G. Valverde, A. Gomes-Silva, C. J. D. C. Moreira et al., "Prevalence and epidemiology of intestinal parasitism, as revealed by three distinct techniques in an endemic area in the Brazilian Amazon," Annals of Tropical Medicine \& Parasitology, vol. 105, no. 6, pp. 413-424, 2011.

[25] A. C. Berne, J. N. Vieira, L. F. D. C. D. Avila, M. M. Villela, M. E. A. Berne, and C. J. Scaini, "Giardia lamblia: diagnóstico com o emprego de métodos microscópicos e Enzyme-linked Immunosorbent Assay (ELISA)," Revista de Patologia Tropical, vol. 43, no. 4, pp. 412-419, 2014.

[26] K. Muhsen and M. M. Levine, "A systematic review and metaanalysis of the association between Giardia lamblia and endemic pediatric diarrhea in developing countries," Clinical Infectious Diseases, vol. 55, no. 4, pp. S271-S293, 2012.

[27] K. L. Kotloff, J. P. Nataro, W. C. Blackwelder et al., "Burden and aetiology of diarrhoeal disease in infants and young children in developing countries (the Global Enteric Multicenter Study, GEMS): a prospective, case-control study," The Lancet, vol. 382, no. 9888, pp. 209-222, 2013.

[28] F. A. Carvalho-Costa, A. Q. Gonçalves, S. L. Lassance, L. M. D. S. Neto, C. A. A. Salmazo, and M. N. Bóia, "Giardia lamblia and other intestinal parasitic infections and their relationships with nutritional status in children in Brazilian Amazon," Revista do Instituto de Medicina Tropical de São Paulo, vol. 49, no. 3, pp. 147-153, 2007.

[29] B. Coronato-Nunes, D. A. Calegar, K. J. L. Monteiro et al., "Giardia intestinalis infection associated with malnutrition in children living in northeastern Brazil," The Journal of Infection in Developing Countries, vol. 11, no. 7, pp. 563-570, 2017.

[30] S. V. Huth, P.-E. Kofoed, and U. Holmskov, "Prevalence and potential risk factors for gastrointestinal parasitic infections in children in urban Bissau, Guinea-Bissau," Transactions of The Royal Society of Tropical Medicine and Hygiene, vol. 113, no. 9, pp. 545-554, 2019.

[31] S. A. Ahmed, M. G. Flórez, and P. Karanis, "The impact of water crises and climate changes on the transmission of protozoan parasites in Africa," Pathogens and Global Health, vol. 112, no. 6, pp. 281-293, 2018. 